\title{
An algorithm for estimating potential deposition of corn pollen for environmental assessment
}

\author{
Shigeto KAWASHIMA ${ }^{1 *}$, Kazuhito MATSUO ${ }^{1}$, Mingyuan DU ${ }^{1}$, Yuichi TAKAHASHI ${ }^{2}$, Satoshi INOUE ${ }^{1}$ \\ and Seiichiro YONEMURA ${ }^{1}$ \\ ${ }^{1}$ National Institute for Agro-Environmental Sciences 3-1-3 Kannondai, Tsukuba 305-8604, Japan \\ ${ }^{2}$ Yamagata Prefectural Institute of Public Health 1-6-6 Tohkamachi, Yamagata 990-0031, Japan
}

The safety and impact on the environment of transgenic crops are important issues, and studies have shown that pollen from transgenic Bt (Bacillus thuringiensis) corn (Zea mays L.) may kill nontarget insects. To develop an algorithm for assessing the environmental effect of transgenic crops, we arranged a field experiment in Tsukuba, Japan. Pollen dispersal and deposition were measured inside and outside a cornfield throughout the flowering period. Weather conditions such as wind speed and direction were measured at the same time. Pollen dispersal peaked 1 week after the start of flowering and continued for 12 days thereafter. The variation in daily pollen dispersal was similar at all observation points. Both pollen dispersal and deposition decreased exponentially with distance from the cornfield on all days. We estimated potential pollen deposition with a quasimechanistic model that incorporates the effects of wind direction, wind speed, and flowering intensity. The daily potential deposition was summed over the flowering period, and then the relationship between distance from the cornfield and the integrated potential deposition was estimated. It was possible to show the effective area of the environmental risk zone posed by genetically modified pollen by combining the distance/deposition relationship with the dose/response relationship derived from a laboratory assay. The algorithm described here can be applied to various wind-pollinated plants to estimate both potential and integrated pollen deposition.

Keywords: transgenic crops / pollen deposition / meteorological effect / estimation model / risk assessment

\section{INTRODUCTION}

The safety and impact on the environment of transgenic crops are important issues. Losey et al. (1999) first suggested that pollen from transgenic Bt (Bacillus thuringiensis) corn (Zea mays L.) might kill nontarget insects, a potentially significant problem. For example, Hellmich et al. (2001) conducted laboratory tests to establish the relative toxicity of $B t$ toxins and pollen from $B t$ corn to monarch butterfly larvae and showed that transgenic corn pollen from event 176 hybrids affected monarch larvae consistently. Zangerl et al. (2001) clarified that event selection was important for reducing the environmental impact of transgenic plants. Much research on pollen dispersal has been undertaken from many biological perspectives: genetic purity and pollination biology (e.g., Morris et al., 1994; Young and Schmitt, 1995), paleoecology and phytopathology (e.g., Jackson and Lyford, 1999; Roche et al., 1995), and allergology (e.g., Asero,
2002; Kawashima and Takahashi, 1995, 2000). Gene flow in wind-pollinated crops has been studied in corn (Tufto et al., 1997) and oilseed rape (Paul et al., 1995; Timmons et al., 1995).

There are two ways to measure pollen dispersal, by direct count of airborne pollen (e.g., McCartney and Lacey, 1991; Raynor et al., 1972a, 1972b) and by gene flow (e.g., Manasse, 1992; Nurminiemi et al., 1998; Paul et al., 1995). Similarly, pollen dispersal can be modeled in two ways. The empirical approach determines mathematical functions and parameters by fitting observed pollen data. The second approach estimates pollen dispersal by using a mechanistic dispersal model. Because mechanistic models require that many parameters be measured, and because they are hard to fit to observed results, quasi-mechanistic models using dispersal kernels have been proposed (Klein et al., 2003; Tufto et al., 1997). The simple model

\footnotetext{
* Corresponding author: sig@affrc.go.jp
} 
for estimating pollen deposition presented here merges wind effects and flowering phenology by using quasimechanistic equations.

Raynor et al. (1972a) compared the dispersal of corn pollen, which has a large grain size, with that of pollens with a smaller grain size. Because of its large grain size, corn pollen falls faster than other types of pollen and lands predominantly near the source. In their study, the concentration of pollen on the ground $60 \mathrm{~m}$ leeward from the source dropped to $1 \%$ of that $1 \mathrm{~m}$ leeward from the source, and the amount of pollen measured in the air $60 \mathrm{~m}$ leeward from the source was $5 \%$ of that $1 \mathrm{~m}$ leeward. The mean deposition speed of the pollen was $33 \mathrm{~cm} . \mathrm{s}^{-1}$. Paterniani and Stort (1974) estimated the pollen dispersal from cornfields of varying sizes and demonstrated that $50 \%$ of the dispersal kernels on an individual plant could result from pollen sources within $12 \mathrm{~m}$.

Pollen dispersal from plants other than corn has also been studied. Raynor et al. (1972b) studied dispersal over relatively short distances by investigating experimentally the process of dispersal and deposition of pollen from timothy (Phleum pratense L.) and determining the relationship between distance from the source and dispersal. Raynor et al. (1973) also measured pollen dispersal from point and line sources to demonstrate the relationship between distance from the source and pollen concentration or deposition rate. Price and Moore (1984) found that a large amount of pollen falls at the center of plateaus, where winds converge, in landscapes where wind from valleys surrounding the plateaus blows upward. Giddings et al. (1997) measured pollen dispersion from perennial ryegrass (Lolium perenne L.) and showed that pollen dispersal is greatly affected by wind direction.

Although many studies measure field-scale pollen dispersion, few have examined pollen dispersal in relation to both the timing of flowering intensity and wind conditions. Thus, we measured both deposited pollen and meteorological conditions simultaneously throughout the flowering period of a cornfield and tabulated and analyzed the observed values. The environmental effect of pollen from plants such as $B t$ corn depends on the extent of total deposition leeward of the source. The amount of pollen deposition is expected be highest when wind speed is high enough for pollen emission and the wind direction is constant throughout the flowering period. We call this hypothetical value, which constitutes the measure of exposure to possible risk, 'potential pollen deposition'. To measure this process, deposition under various wind directions and wind speeds must be predicted. Therefore, we developed an assessment method for calculating pollen deposition that takes into account both wind condi- tions and the flowering characteristics of the plants emitting the pollen. This model was then used to predict daily potential deposition and to determine the relationship between distance from a cornfield and the amount of possible pollen deposition.

\section{RESULTS}

\section{Pollen dispersal and deposition}

The variation in the airborne pollen count over time is shown in Figure 1. The pollen count was particularly high at Point $\mathrm{C}$, the closest leeward point of pollen observation. It peaked 1 week after dispersal began, and then rapidly dropped over the 4 days that followed. Dispersal continued to be observed 12 days after the peak despite the low count during the latter half of the dispersal period. When the change in dispersed pollen count according to distance from the cornfield was surveyed, the count was found to be greatest at $C$ on almost all days, and the next largest amounts were obtained at $\mathrm{A}$ and $\mathrm{B}$, in that order. At the points outside the cornfield, the counts decreased rapidly at the points closer to the cornfield and decreased slowly at the points far from the cornfield.

The variation in the deposited pollen count over time is shown in Figure 2. Deposited pollen increased and decreased in a pattern similar to that of the dispersed pollen. The daily changes at $\mathrm{A}$ and $\mathrm{B}$ inside the cornfield and at $\mathrm{C}$ near the cornfield were similar. On the peak day, the daily deposited pollen count in and near the cornfield exceeded 1000 grains. $\mathrm{cm}^{-2}$. Subsequently, the count tended to be greatest at $\mathrm{C}$. We attribute the decrease on 4 August to the precipitation that fell during the previous night; the deposited count was lower than the dispersed pollen count because the slide for the former was directly exposed to the rain (see Materials and methods). When the change in the deposited pollen count according to distance from the cornfield was surveyed, we found that particularly high counts occurred at A, B, and C on most days.

\section{Meteorological conditions}

The variations with time of the wind speed at 4 heights above the ground are shown in Figure 3A. The mean wind speed during the observation period was $2.1 \mathrm{~m} . \mathrm{s}^{-1}$ at $4 \mathrm{~m}$ above the ground. It ranged from 1.5 to $2.0 \mathrm{~m} . \mathrm{s}^{-1}$ at the beginning and during the latter half of the period, but a strong wind of nearly $3.0 \mathrm{~m} . \mathrm{s}^{-1}$ prevailed during the 6-day period from 27 July to 1 August. The mean wind 


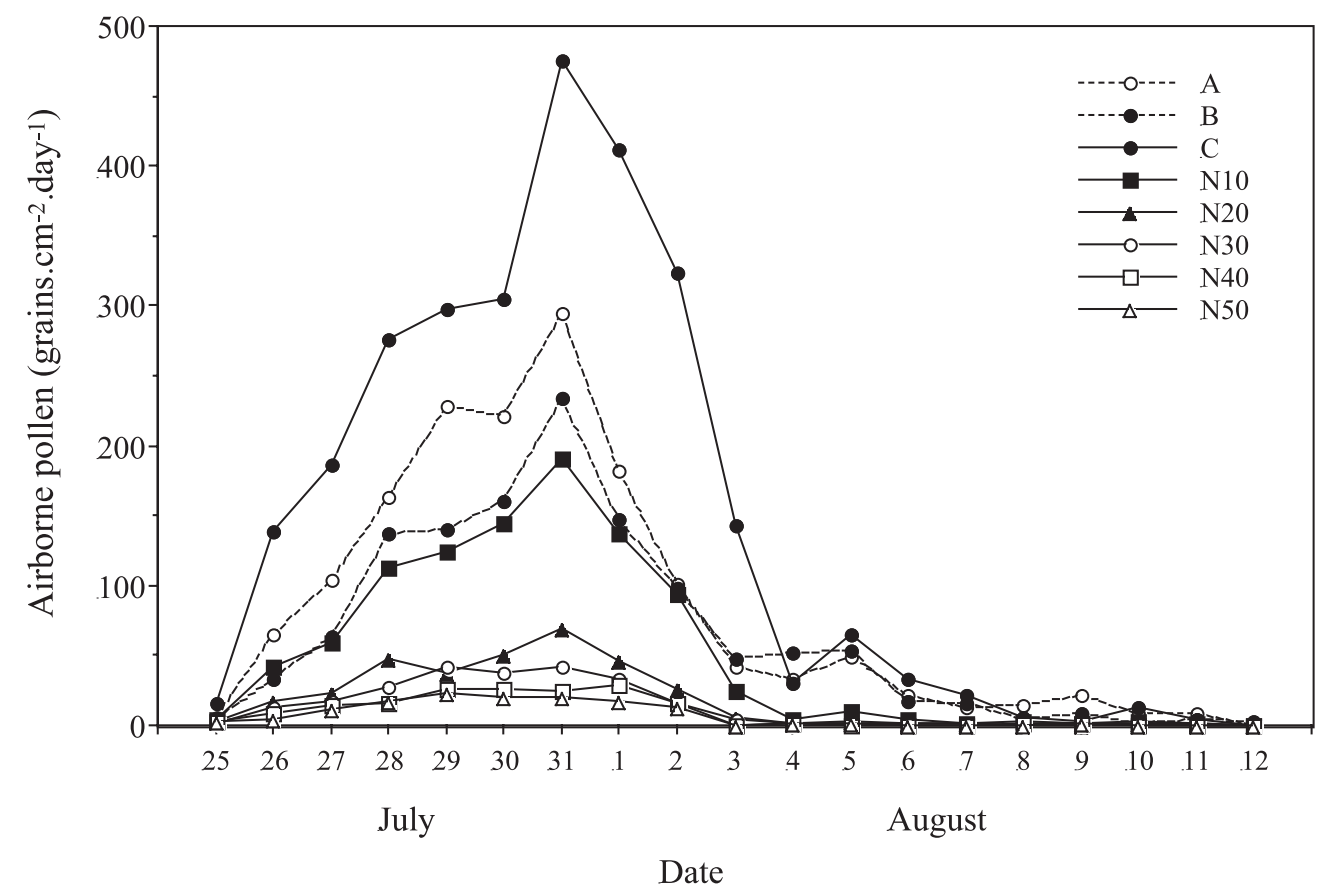

Figure 1. Variation in airborne pollen between 25 July and 12 August. Pollen dispersal peaked 1 week after the start of flowering and continued for 12 days thereafter. A and B correspond to the sampler locations within the cornfield. C, N10, N20, N30, N40, and N50 correspond to the sampler locations outside and leeward of the cornfield (Fig. 7).

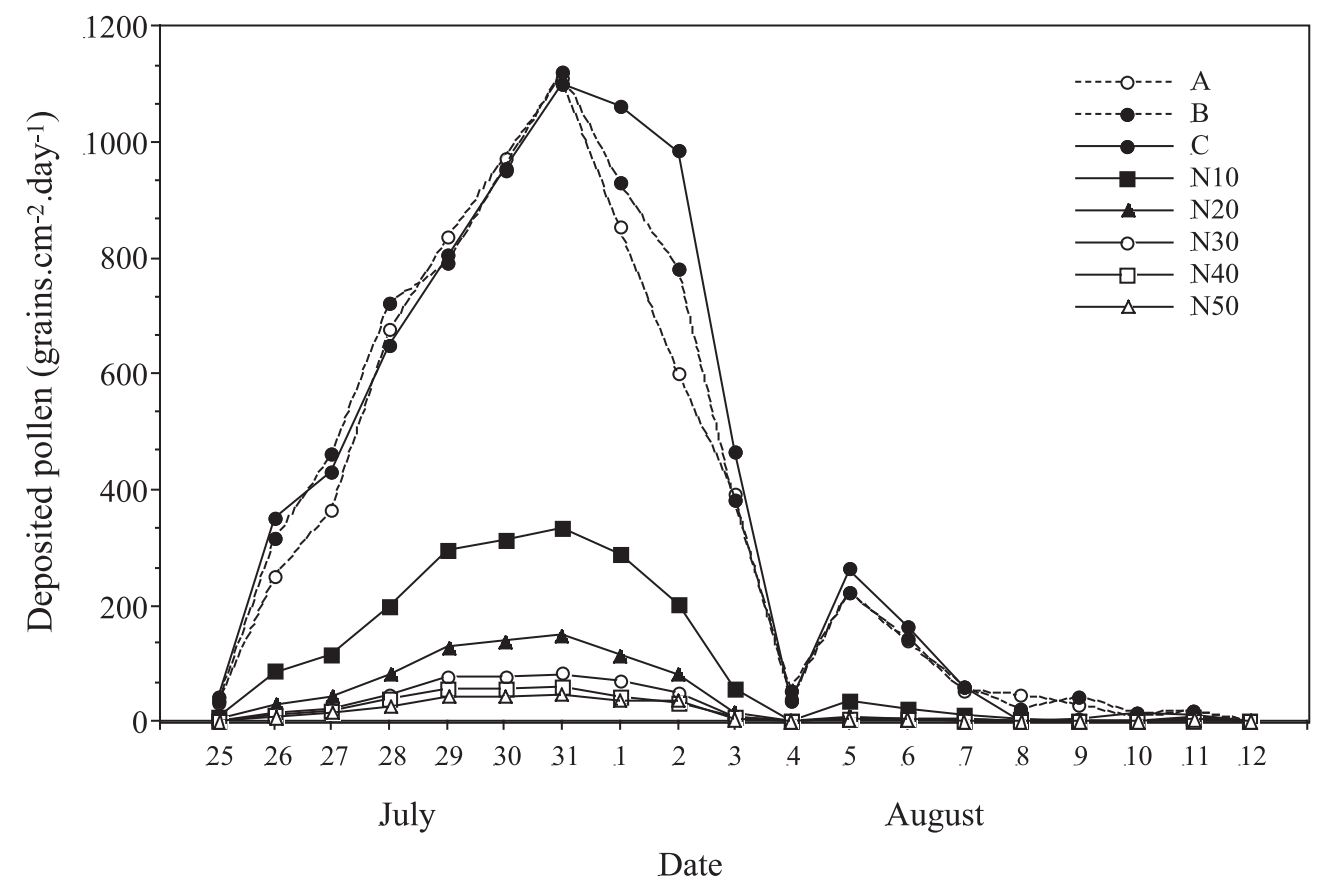

Figure 2. Variation in deposited pollen between 25 July and 12 August. Large numbers of pollen grains were recorded within and near the border of the cornfield. A and B correspond to the sampler locations within the cornfield. C, N10, N20, N30, N40, and N50 correspond to the sampler locations outside and leeward of the cornfield (Fig. 7). 

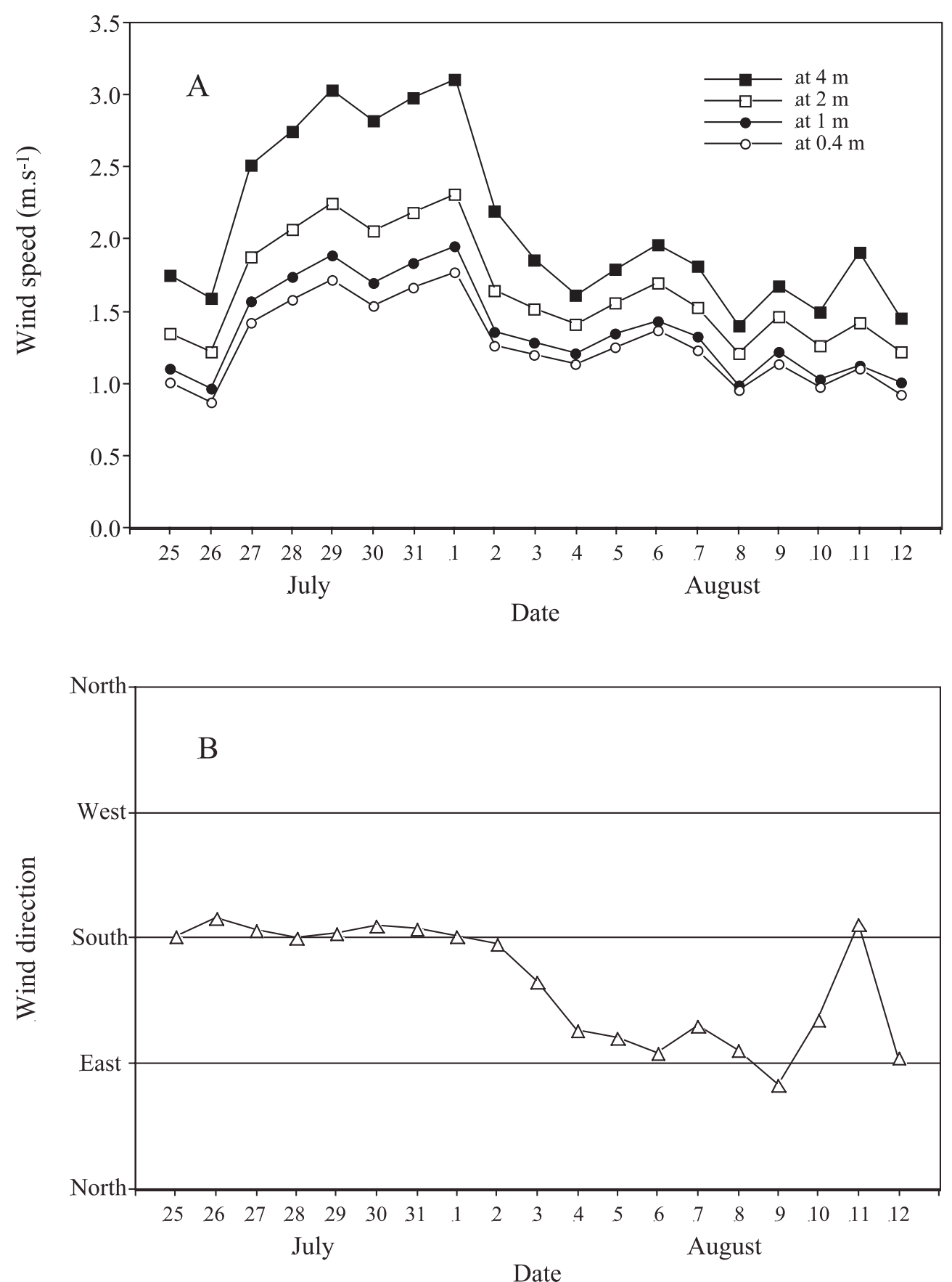

Figure 3. Daily variation in wind conditions. (A) Wind speed measured at 4 heights above the ground. (B) Wind direction measured at $4 \mathrm{~m}$ above the ground.

speed during the experiment differed little from the mean wind speed, $2.4 \mathrm{~m} . \mathrm{s}^{-1}$, measured during corresponding periods from 1990 to 1999 by an instrument $6 \mathrm{~m}$ above the ground at Tateno, Tsukuba, near the site of the experiment.
The daily variation of the wind direction at $4 \mathrm{~m}$ above the ground is shown in Figure 3B. The first half of the observation period was characterized by a very stable southern wind, which on 3 August began shifting gradually to become easterly. A southeastern wind prevailed 
during the latter half of the period. At Tateno during the same period during 1990-1999, the average wind direction was southeast. Therefore, as with wind speed, wind direction during the experiment was similar to average conditions for recent years. The stable southern wind during the first half of the experiment was very favorable in terms of the positioning the experimental field and pollen samplers. It was also advantageous to our analysis of the effect of wind on pollen deposition that the experiment was performed during a period of stable strong southerly wind followed by a period with gradually shifting wind direction.

The mean daily temperature throughout the experiment was about $28{ }^{\circ} \mathrm{C}$, with hot days prevailing. The first half of the experimental period was slightly warmer than the latter half, and the temperature on 27 July was particularly high at $29.6{ }^{\circ} \mathrm{C}$. The temperature on 10 August, conversely, was particularly low for the period at $26^{\circ} \mathrm{C}$. The relative humidity ranged from $70 \%$ to $80 \%$ and changed inversely over time in relation to the temperature change. The relative humidity on 10 August was a particularly high $93 \%$. The amount of solar radiation was above $18 \mathrm{MJ} . \mathrm{m}^{-2}$ on all days other than 10 August. There was a particularly high amount of solar radiation, above

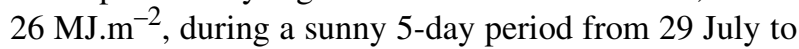
2 August. Precipitation was noted on 4 and 10 August. The precipitation on 4 August was concentrated in the night and was therefore considered to have little effect on the pollen dispersal.

\section{Pollen deposition estimation model}

When considering the effects of pollen on the environment, it is important to estimate the total deposition when wind conditions are favorable to pollen dispersal and concentrated deposition throughout the flowering period. High wind speeds favor pollen emission, and a stable wind direction leads to concentrated deposition leeward of a field. Actual deposition is affected by the wind speed and direction. Therefore, we developed a model that factors in the effects of wind on the deposited pollen counts leeward of the pollen source. This model allows the user to predict leeward deposition in the event of changes in wind speed and direction. The premises and assumptions for the model for estimating daily pollen deposition on the leeward side are as follows:

(1) The pollen measurements used were the daily totals of the deposited pollen counts obtained at the 6 measurement points leeward of the cornfield $(1,10,20,30,40$, and $50 \mathrm{~m}$ from the cornfield). The daily total counts of 6 points were used as the target variable.
(2) The period when the male flowers of any individual corn plant became elongated and capable of releasing pollen is about 1 week, but the flowering period of a cornfield as a whole is longer owing to disparities in the growth of individual plants. We refer to the number of flowering plants as the flowering strength of the cornfield, and we approximate the change in flowering strength over time by a parabolic curve.

(3) The number of deposited pollen grains is proportional to the flowering strength.

(4) The number of deposited pollen grains is proportional to the wind speed.

(5) The number of deposited pollen grains decreases in proportion to the absolute value of the difference between the wind direction and the direction of the center axis connecting the pollen sampling points with the cornfield. A southerly wind (8 on an azimuth scale with 16 divisions) blows parallel to the center axis, and an easterly or westerly wind (4 or 12 on an azimuth scale with 16 divisions) blows perpendicular to the center axis.

(6) There were few visibly flowering individuals among the population on 25 July, the day on which pollen was observed for the first time. The flowering strength of the cornfield as a whole on 24 July was therefore taken to be zero.

These premises and assumptions are represented by the following equations:

$$
\begin{gathered}
P=\mathrm{a} S_{p} W_{s}\left(1-\mathrm{d} W_{d d}\right)+\mathrm{e} \\
S_{p}=\mathrm{b} t^{2}+\mathrm{c} t
\end{gathered}
$$

where $P$ is deposited pollen count (grains. $\mathrm{cm}^{-2} \cdot$ day $^{-1}$ ), $S_{p}$ is the flowering strength of the cornfield as a whole (number of individual plants), $W_{s}$ is the wind speed $\left(\mathrm{m} . \mathrm{s}^{-1}\right.$ ), and $W_{d d}$ is the absolute value of difference between the wind direction and the direction of the center axis (degree). Wind speed and wind direction are both daily averaged values, $t$ is the day number, and a, b, c, d, and e are constants.

\section{Application of the model to observed data}

Expanding on and reformulating equations (1) and (2) gives

$$
P=\mathrm{C}_{1} W_{d d} W_{s} t^{2}+\mathrm{C}_{2} W_{d d} W_{s} t+\mathrm{C}_{3} W_{s} t^{2}+\mathrm{C}_{4} W_{s} t+\mathrm{C}_{0}
$$

Multiple regression analysis based on the observed data was performed with $P$ as the target variable to calculate 
the 5 coefficients $\left(\mathrm{C}_{0}, \mathrm{C}_{1}, \mathrm{C}_{2}, \mathrm{C}_{3}\right.$, and $\left.\mathrm{C}_{4}\right)$. The target variable $P$ was the daily total deposited pollen count at the leeward sampling points $(C, N 10, N 20, N 30, N 40$, and N50). There were thus 19 cases (19 days), the multiple correlation coefficient $R$ was 0.984 , and the coefficient of determination (contribution ratio) $R^{2}$ was 0.968 . The coefficient of determination $R^{2}$ adjusted by the degrees of freedom was 0.896 , and the standard error was 126. In order to assess the adaptability of the model, pollen deposition was then estimated using equation (3) with the observed wind speeds and wind directions and the calculated coefficients. Figure 4 shows the relationship between observed and estimated pollen deposition. This simple model explains about $90 \%$ of the variation in the observed pollen deposition by using the wind conditions. The daily variation in the number of observed and estimated pollen grains is shown in Figure 5. This model explains well the general variation over time in pollen deposition in the leeward direction.

\section{Prediction of potential pollen deposition}

During the first half of the observation period, both wind speed and direction were well suited for pollen emission and concentrated deposition, but during the latter half, the

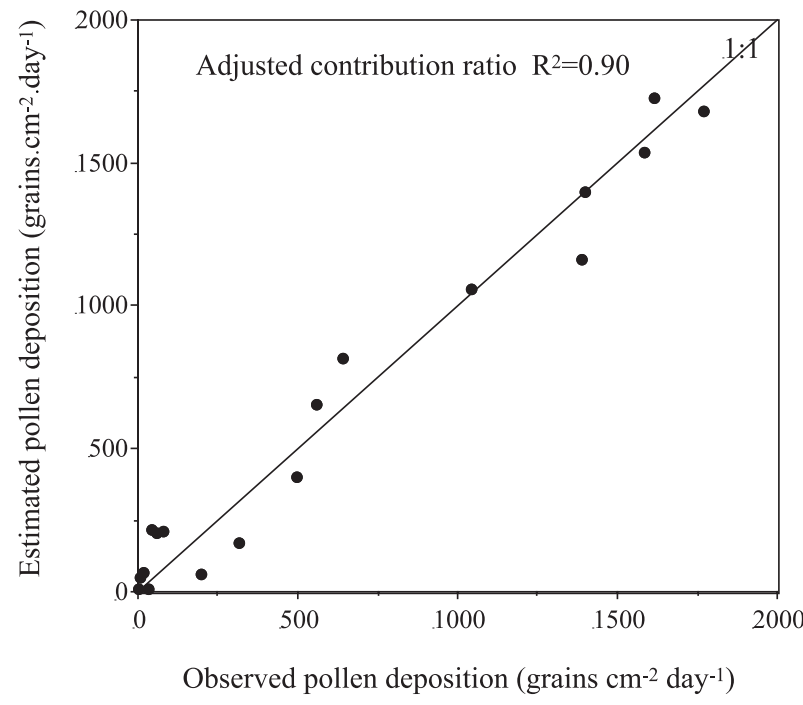

Figure 4. Relationship between the observed and estimated pollen deposition. The adjusted contribution ratio, $R^{2}$, is 0.90 .

wind speed slowed slightly and the wind direction drifted gradually toward the east. For the environmental assessment of total pollen deposition, it is important to estimate potential pollen deposition, that is, deposition under ideal conditions. Potential deposition occurs leeward of the

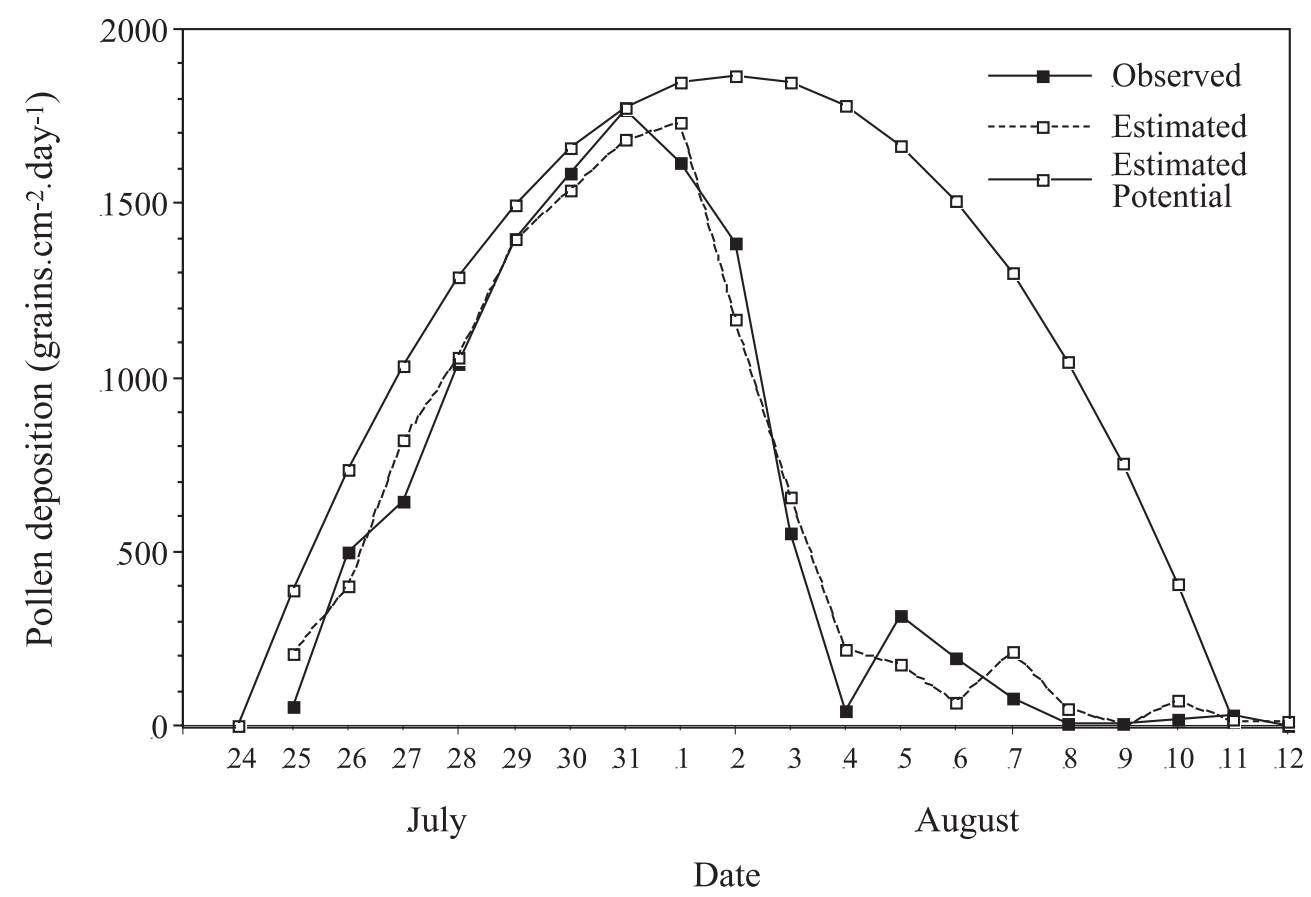

Figure 5. Daily variation in observed and estimated pollen deposition. Black squares with a solid line show observed pollen deposition; white squares with a dashed line show estimated pollen deposition using the observed wind conditions; and white squares with a solid line show the estimated potential deposition under ideal wind conditions. 
pollen source when a strong wind blows continuously and the wind direction is constant throughout the flowering period of the plant community. The wind speed must be reasonable in relation to the meteorological statistics in the area of interest.

A review of past meteorological data for the Kannondai area of Tsukuba city, where the experiment was conducted, revealed that a mean wind speed of $3 \mathrm{~m} . \mathrm{s}^{-1}$ or above for the period from the last third of July to the first third of August was observed only once in 20 years. Using the regression equation (3), we estimated the potential deposition at the 6 leeward points by assuming a constant south wind and a daily mean wind speed of $3 \mathrm{~m} . \mathrm{s}^{-1}$. The obtained values were the daily potential depositions of pollen on the leeward side of the field. The estimated potential deposition over the days of the experiment is shown in Figure 5. The shape of the curve reflects the assumption that the flowering strength of the cornfield is approximated by a parabolic curve. The maximum potential deposition occurs a few days after the maximum observed deposition. Observed pollen deposition during the latter half of the field experiment was greatly reduced by varying wind direction and speed.

\section{Change in integrated potential deposition of pollen with distance from the cornfield}

The model above is used to study the relationship between distance from the cornfield and potential deposition of corn pollen. The integrated potential deposition, determined at each observation point by integrating the daily potential deposition over the entire flowering period, serves as an index for determining exposure to possible risk when the extent of the pollen effect is considered. We discuss its change with increasing distance from the cornfield.

The relationship between the daily pollen deposition at each leeward point and that at point $\mathrm{C}$ was investigated. The results are shown in Table 1. Each relationship was linear $(P<0.0001)$. The regression parameters are statistically constant. Thus, the normalized decreasing pattern of pollen deposition with distance from the cornfield did not vary from day to day, and the pattern can be represented by the integrated deposition at each observation point.

The ratio of total potential deposition (the sum of daily potential deposition values over the entire period, shown in Figure 5) to the total measured deposition (the sum of the measured deposition values over the entire period, shown in Figure 5) was 2.0. Thus, the measured deposition at each measurement point over the entire
Table 1. Results of the regression analysis of daily pollen deposition at each point against that at point $C$. The second column contains the coefficient of determination, $R^{2}$, adjusted by the degrees of freedom. In the third through sixth columns, the regression coefficients (slopes and intercepts) are listed with standard errors (SE).

\begin{tabular}{lccccc}
\hline \hline Pollen sampling & Adjusted & \multicolumn{5}{c}{ Regression coefficients } \\
\cline { 3 - 6 } point & $\mathrm{R}^{2}$ & Slope & SE & Intercepts & SE \\
\hline N10 & $0.92^{* * *}$ & 0.294 & \pm 0.021 & -11.4 & \pm 11.8 \\
N20 & $0.88^{* * *}$ & 0.126 & \pm 0.011 & -7.1 & \pm 6.4 \\
N30 & $0.89^{* * *}$ & 0.073 & \pm 0.006 & -4.0 & \pm 3.6 \\
N40 & $0.86^{* * *}$ & 0.052 & \pm 0.005 & -2.7 & \pm 2.8 \\
N50 & $0.90^{* * *}$ & 0.041 & \pm 0.003 & -2.1 & \pm 1.9 \\
\hline
\end{tabular}

$* * * P<0.0001$.

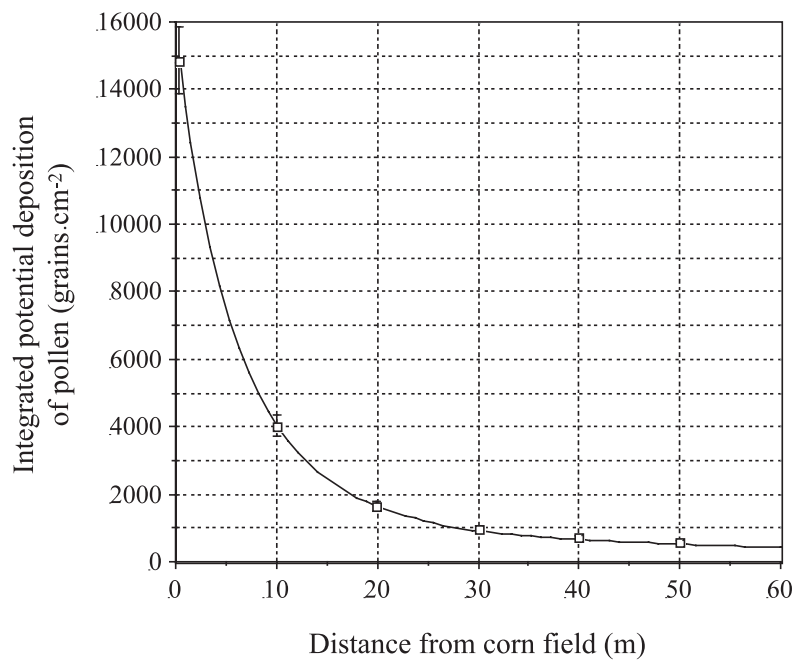

Figure 6. Change in the integrated potential pollen deposition with distance from the cornfield. White squares and error bars show the estimated values and three times the standard error. The curve is the fitted exponential function, which includes a third-order polynomial.

flowering period can be doubled to estimate the integrated potential deposition at each measurement point. Figure 6 shows the change in the integrated potential deposition of pollen with distance from the cornfield. The relationship between integrated potential deposition ( $y$; grains. $\mathrm{cm}^{-2}$ ) and the distance leeward from the cornfield $(x ; \mathrm{m})$ was fitted to an exponential function, which includes a third-order polynomial, as follows:

$$
y=14791 \exp \left(-0.158 x+0.00275 x^{2}-0.0000183 x^{3}\right) \text {. }
$$


Although this relation might also be explained by other similar functions, it is generally preferable to express the relationship between distance and pollen count by an equation having as few parameters as possible. In this case, however, pollen deposition data was given top priority, and equation (4) was therefore chosen so that such data could be interpolated with high accuracy. Using this curve, the integrated potential deposition can be estimated at any given distance from the cornfield.

\section{DISCUSSION AND CONCLUSION}

Dispersed and deposited pollen counts were measured along with meteorological conditions both in and leeward of a cornfield throughout the flowering period. The cornfield was $40 \mathrm{~m}$ wide $\times 90 \mathrm{~m}$ long, and the prevailing wind blew perpendicular to the long side. The numbers of dispersed and deposited pollen grains decreased exponentially with increasing distance from the cornfield on every day of the experiment. A relatively simple quasi-mechanistic model based on the observed data and analysis of the relationship between wind conditions and the deposited pollen count was developed to estimate daily total deposition leeward of the cornfield. The environmental risk zone near the cornfield was determined by considering the relationship between distance from the cornfield and integrated potential deposition determined by using the model together with pollen deposition concentrations found to be effective in an insect development experiment (Hellmich et al., 2001; Sears et al., 2001). Taking the field discussed in this report as an example, the safe range would begin $10 \mathrm{~m}$ away from the field if a total pollen deposition value of up to 4000 grains. $\mathrm{cm}^{-2}$ was not problematic. For values of 2000, 1000, or 500 grains.cm ${ }^{-2}$, the safe zone would begin 20,30, or $55 \mathrm{~m}$ from the boundary of the field, respectively.

The algorithm presented here can be used to estimate the daily potential deposition and integrated potential deposition of pollen from a variety of plants. A summary of the procedure to be used follows:

(1) Measure the deposited pollen count throughout the flowering period at several observation points leeward of the source field with respect to the prevailing wind. In addition, record meteorological conditions: wind speed, wind direction, air temperature, and humidity.

(2) Estimate the flowering period for the whole field from observations of flowering conditions and the deposited pollen count.

(3) Estimate the model parameters by substituting the observed data into the model developed in this report.
(4) Determine a reasonable high wind speed from past wind speed records for the flowering period of the plant in question in the area under consideration. As this is a matter of probability, for example, select the high wind speed that would be expected to blow continuously during the period only once in 20 years.

(5) Estimate the daily potential deposition by assuming a reasonable high wind speed with invariant wind direction.

(6) Calculate the total potential deposition, that is, potential deposition summed over the entire flowering period; and the total measured deposition, that is, the measured deposition summed over the entire flowering period; and the ratio between the two.

(7) Multiply the ratio determined in the previous step by the total measured deposition at each measurement point over the entire flowering period to estimate the integrated potential deposition at each measurement point.

Once customized, this model can be used to estimate the relationship between distance from the field and the integrated potential deposition of target pollen in the applicable area in view of the wind characteristics in the area, as long as the kind of crop and the size of the source field remain unchanged.

In the algorithm presented here, the effect of field size is reflected through the measured pollen count values. We hope to treat that effect as a variable of the model in the future. Further experiments must be performed and mechanistic simulations must be used in order to determine how the deposited pollen count leeward of a field varies as the size of the field changes. However, research on contaminant diffusion (Arya, 1999) suggests the following. Airborne pollen concentrations should increase in areas near the leeward boundary of a field when the dimension of the field parallel to the wind direction increases, but a doubling of that dimension does not cause a doubling of the airborne pollen concentration. The airborne pollen concentration at a point near the leeward boundary of a field would be little affected by an increase in the dimension of the field perpendicular to the direction of the wind. For the first $100 \mathrm{~m}$ from the field boundary, for example, an increase or decrease in the dimension perpendicular to the wind direction would result in little increase or decrease in the airborne pollen concentration in the area under consideration. In the model, the effect of field size can be incorporated into parameter $S p$. This parameter will also be affected by wet deposition by precipitation. The algorithm and parameters of our model could be improved by considering further the effects of field size and precipitation. In addition, 
to construct a mechanistic model able to predict gene flow, it would be necessary to determine the actual deposition rate on the surfaces of target plants. Although there is merit in the present quasi-mechanistic model, it is a long way from being able to predict the levels of gene flow that might be expected to result from pollen dispersal.

To estimate the maximum possible deposition of the target pollen, all directions from the source field must be taken into account. Deposition of pollen to the leeward will continue as long as the wind continues to blow. In this report, the relationship between the distance from the field and deposition of pollen was considered with respect to the direction of the prevailing wind. However, in actuality, the spatial distribution of pollen deposition must be assessed over the area leeward of the field. This issue must be addressed through simulations and further field experiments. In addition, large volumes of pollen count data are needed to construct more accurate models, but the collection of such data is very labor intensive. The development of a method capable of easily and quickly measuring airborne pollen amounts is a key task for the future.

\section{MATERIALS AND METHODS}

\section{Experimental field}

We collected meteorological data and biological data from a field experiment to use for modeling deposition of pollen from a corn field. The field observations were made at the National Institute for Agro-Environmental Sciences at Kannondai, Tsukuba city, Japan. Figure 7 shows the arrangement of the measuring instruments at the study site. Typical data suitable for the analysis was obtained during a 19-day period from 25 July to 12 August 1999. White dent corn was sown on 25 May 1999 in the source field, which measured $3600 \mathrm{~m}^{2}$ in area. The plot was $40 \mathrm{~m}$ wide and $90 \mathrm{~m}$ long, and the prevailing wind direction was perpendicular to the length. The mean plant height over the period of observation was $3.1 \mathrm{~m}$, the density of individual plants with male flower spikes was 536 plants per $100 \mathrm{~m}^{2}$, and the estimated total number of corn plants in the plot was 19 460. The density of plants in the plot was within the range of normal plant density in corn plots (370-550 plants per $100 \mathrm{~m}^{2}$; Hoshikawa, 1989). The observations were made during a period of fine weather with stable southerly prevailing winds following the Japanese rainy season. The leeward field (Fig. 7) north of the experimental cornfield was

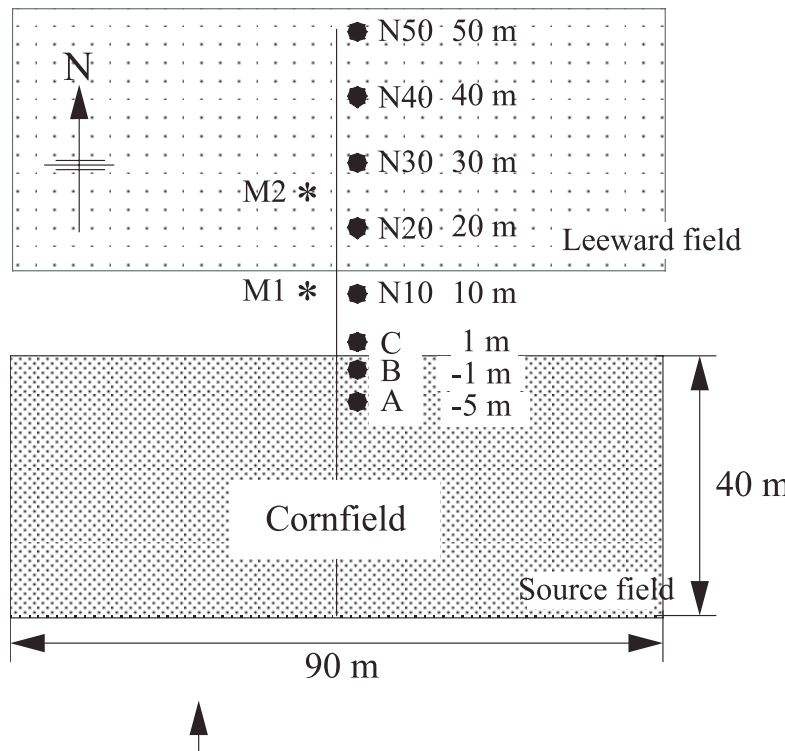

Prevailing wind direction

Figure 7. Arrangement of the measuring instruments at the study site. $\bullet$ : Pollen observation points with Durham samplers. *: Meteorological observation points.

planted with soybeans, which at the time of the experiment were in an early stage of development. No other flowering corn was growing near the experimental field during the experimental period. White dent corn pollen is spherical with a grain diameter of approximately $100 \mu \mathrm{m}$.

\section{Pollen measurement}

Durham pollen samplers (Durham, 1946) were placed in 2 locations (A and $\mathrm{B}$ ) within the cornfield and in 6 locations (C, N10, N20, N30, N40, and N50) outside and leeward of the cornfield (Fig. 7). Microscope slides $(76 \times$ $26 \mathrm{~mm}^{2}$ ) on which vaseline had been thinly spread were attached to each sampler at heights of 120 and $125 \mathrm{~cm}$ above the ground. The slides at $120 \mathrm{~cm}$, the height normally used to measure airborne pollen counts, were placed between upper and lower metal disks. The pollen count measured at this height was defined as the airborne pollen count. The slides positioned $125 \mathrm{~cm}$ above the ground, on the other hand, were placed in the center of the upper surface of the upper metal disk. Because that position is exposed to rain, slides are not generally placed there, but we chose to obtain measurements at this position as well in order to estimate pollen deposition on the 
leaf surfaces of plants. The pollen count on the exposed slides was thus defined as the deposited pollen count. Fortunately, little rain fell during the experimental period.

The slides were replaced every morning at around 10:00 a.m. The pollen on the slides was stained with Carberla's solution and covered with an $18 \times 18 \mathrm{~mm}$ cover slip. All pollen under the cover slip was subsequently counted under a microscope at 100 to $200 \times$. The calculated pollen density (grains. $\mathrm{cm}^{-2}$ ) was used for the analysis.

The pollen counts obtained from the slides were tabulated on a per-day basis. The pollen data obtained from the protected slides attached to the Durham samplers at $120 \mathrm{~cm}$ height, referred to as the airborne pollen count, were considered to correspond to the amount of pollen that would be deposited on the surfaces of the inner leaves of plants. The pollen data obtained from the exposed slides attached at $125 \mathrm{~cm}$ height, referred to as deposited pollen count, were considered to correspond to the amount of pollen settling on the upper leaf surfaces of plants.

\section{Meteorological measurements}

Meteorological measurements were taken at Point M1, about $10 \mathrm{~m}$ leeward of the cornfield, and at Point M2, about $25 \mathrm{~m}$ leeward. At Point M1, wind speed was measured at 3 heights, 1, 2, and $4 \mathrm{~m}$ above the ground, wind direction was measured $4 \mathrm{~m}$ above the ground, and air temperature and humidity were recorded at $1.5 \mathrm{~m}$ above the ground. At Point M2, wind speed and direction were measured at $0.4 \mathrm{~m}$ above the ground. All wind speed and direction sensors were photoelectric 3-cup anemometers and photoelectric wind vanes, respectively (Makino Applied Instruments Inc., Tokyo, Japan). The temperature and humidity sensor used was a platinum resistancetype thermometer installed in a ventilated tube. The measurement data were recorded by a SOLAC III data logger (EKO Instruments Trading Co., Ltd, Tokyo, Japan). Meteorological data collected at a meteorological tower operated by the National Institute for Agro-Environmental Sciences, $300 \mathrm{~m}$ east of the cornfield, were used to determine the weather conditions before and after the period of field observation.

\section{ACKNOWLEDGMENTS}

We are deeply indebted to Dr. Tsuyoshi Mitamura of the Plant Management Section of the National Institute for Agro-Environmental Sciences for help in integrating research from a variety of fields. We were greatly inspired by discussions with Dr. Masaharu Matsui of the Insect Management Section of the Institute. Finally, Ms. Ikuko Utagawa of the Atmospheric Research Laboratory at the Institute performed many tasks on our behalf. We express our thanks to all of you.

Received September 17, 2004; accepted February 13, 2005.

\section{REFERENCES}

Arya SP (1999) Air pollution meteorology and dispersion. Oxford University Press, New York

Asero R (2002) Birch and ragweed pollinosis north of Milan: a model to investigate the effects of exposure to new airborne allergens. Allergy 57: 1063-1066

Durham OC (1946) The volumetric incidence of atmospheric allergens. III. Rate of fall of pollen grains in still air. J. Allergy 17: $70-78$

Giddings GD, Sackville Hamilton NR, Hayward MD (1997) The release of genetically modified grasses. Part 1: pollen dispersal to traps in Lolium perenne. Theor. Appl. Genet. 94: 1000-1006

Hellmich RL, Siegfried BD, Sears MK, Stanley-Horn DE, Daniels MJ, Mattila HR, Spencer T, Bidne KG, Lewis LC (2001) Monarch larvae sensitivity to Bacillus thuringiensispurified proteins and pollen. Proc. Natl. Acad. Sci. U.S.A. 98: 11925-11930

Hoshikawa K (1989) Zea. In Horita et al., eds, Dictionary of Useful Plants of the World, Heibonsha, Tokyo, pp 1116-1119

Jackson ST, Lyford ME (1999) Pollen dispersal models in Quaternary plant ecology: assumptions, parameters, and prescriptions. Bot. Rev. 65: 39-75

Kawashima S, Takahashi Y (1995) Modelling and simulation of mesoscale dispersion processes for airborne cedar pollen. Grana 34: 142-150

Kawashima S, Takahashi Y (2000) An improved simulation of mesoscale dispersion of airborne cedar pollen using a flowering-time map. Grana 38: 316-324

Klein EK, Lavigne C, Foueillassar X, Gouyon PH, Laredo C (2003) Corn pollen dispersal: Quasi-mechanistic models and field experiments. Ecol. Monogr. 73: 131-150

Losey JE, Raynor LS, Carter ME (1999) Transgenic pollen harms monarch larvae. Nature 399: 214

Manasse RS (1992) Ecological risks of transgenic plants: effects of spatial dispersion on gene flow. Ecol. Appl. 2: 431438

McCartney HA, Lacey ME (1991) Wind dispersal of pollen from crops of oilseed rape (Brassica napus L.). J. Aerosol Sci. 22: $467-477$ 
Morris WF, Price MV, Waser NM, Thomson JD, Thomson B, Stratton DA (1994) Systematic increase in pollen carryover and its consequences for geitonogamy in plant populations. Oikos 71: 431-440

Nurminiemi M, Tufto J, Nilsson NO, Rognli OA (1998) Spatial models of pollen dispersal in the forage grass meadow fescue. Evol. Ecol. 12: 487-502

Paterniani E, Stort AC (1974) Effective maize pollen dispersal in the field. Euphytica 23: 129-134

Paul EM, Thompson C, Dunwell JM (1995) Gene dispersal from genetically modified oilseed rape in the field. Euphytica 81: 283-289

Price MDR, Moore PD (1984) Pollen dispersion in the hills of Wales: A pollen shed hypothesis. Pollen Spores 26: 127-136

Raynor GS, Ogden EC, Hayes JV (1972a) Dispersion and deposition of corn pollen from experimental sources. Agron. J. 64: 420-427

Raynor GS, Ogden EC, Hayes JV (1972b) Dispersion and deposition of timothy pollen from experimental sources. Agric. Meteorol. 9: 347-366

Raynor GS, Ogden EC, Hayes JV (1973) Dispersion of pollens from low-level, crosswind line sources. Agric. Meteorol. 11: 177-195
Roche HM, Alexander AD, Maltby AD (1995) Dispersal and disease gradients of anther-smut infection of Silene alba at different life stages. Ecology 76: 1863-1871

Sears MK, Hellmich RL, Stanley-Horn DE, Oberhauser KS, Pleasants JM, Mattila HR, Siegfried BD, Dively GP (2001) Impact of Bt corn pollen on monarch butterfly populations: A risk assessment. Proc. Natl. Acad. Sci. U.S.A. 98: $11937-11942$

Timmons AM, O'Brien ET, Charters YM, Dubbels SJ, Wilkinson MJ (1995) Assessing the risks of wind pollination from fields of genetically modified Brassica napus ssp. oleifera. Euphytica 85: 417-423

Tufto J, Engen S, Hindar K (1997) Stochastic dispersal processes in plant populations. Theor. Popul. Biol. 52: 16-26

Young KA, Schmitt J (1995) Genetic variation and phenotypic plasticity of pollen release and capture height in Plantago lanceolata. Funct. Ecol. 9: 725-733

Zangerl AR, McKenna D, Wraight CL, Carroll M, Ficarello P, Warner R, Berenbaum MR (2001) Effects of exposure to event 176 Bacillus thuringiensis corn pollen on monarch and black swallowtail caterpillars under field conditions. Proc. Natl. Acad. Sci. U.S.A. 98: 11908-11912
To access this journal online: www.edpsciences.org 